\title{
Antifungal activity of galectin-3 against black Aspergilli
}

\author{
Daniela Jakšić, Maja Šegvić Klarić, Sanja Dabelić \\ University of Zagreb, Faculty of Pharmacy and Biochemistry, Zagreb, Croatia
}

Objectives. The Aspergillus section Nigri comprises several species widely distributed in the environment. Apart from their use in food production and biotechnology, many species are plant pathogens, mycotoxin (ochratoxin $A$ and fumonisins) producers, and causative agents of respiratory infections in immunocompromised patients as well as otomycosis and keratomycosis in tropical and subtropical regions [1].

Galectin-3 (Gal-3) is a pleiotropic protein that primarily binds to lactose and it is involved in a variety of cellular processes including interaction with pathogens, immune response and cell death. Several studies indicated possible antimicrobial action of Gal-3 against bacteria and yeasts but antifungal activity against filamentous fungi such as Aspergilli is not known [2].

The aim of this study was to test antifungal activity of Gal-3 in comparison to amphotericin $\mathrm{B}(\mathrm{AMB})$ against $A$. brasiliensis ATCC 16404 and 5 airborne species of black Aspergilli ( $A$. piperis, A. tubingensis, A. welwitchiae, A. niger, A. luchuensis) from microbial collection of University of Zagreb, Faculty of pharmacy and biochemistry, Department of microbiology.

$\rightarrow$ A. brasiliensis ATCC $16404+$ Gal-3

$\rightarrow$ A. piperis + Gal-3

- black Aspergilli + LPS

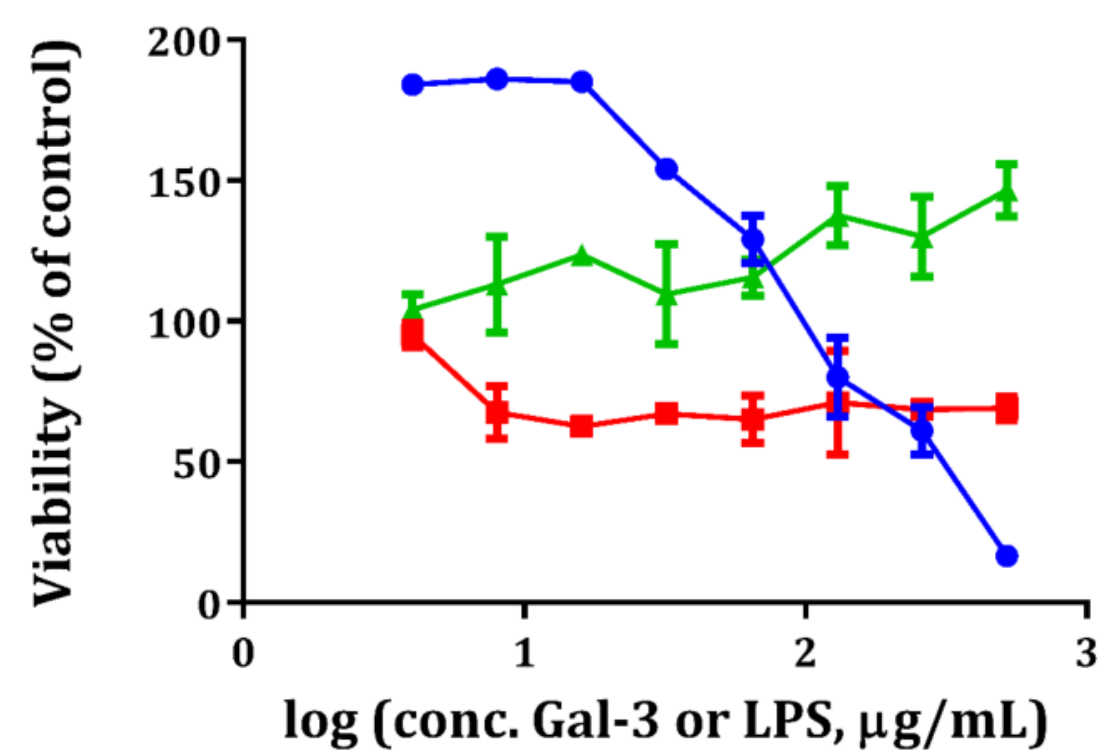

Fig. 1. Viability of black Aspergilli after the treatment with Gal-3 and LPS.

Results. According to minimum inhibitory concentration (MIC) of AMB, A. brasiliensis ATCC $16404(1 \mu \mathrm{g} / \mathrm{mL})$ followed by $A$. piperis $(0.5 \mu \mathrm{g} / \mathrm{mL})$ were the most resistant black Aspergilli (Table 1). MIC of AMB for the rest of tested strains was 0.25 $\mu \mathrm{g} / \mathrm{mL}$. Opposite to AMB, Gal-3 was efficient only against $A$. brasiliensis strain $(520 \mu \mathrm{g} / \mathrm{mL})$. All applied concentrations of Gal-3 decreased viability of $A$. piperis by $30 \%$ (Fig.1), while other black Aspergilli were resistant to Gal-3. Additionally, black Aspergilli were treated with LPS because it may remain in solution after the production of Gal-3. It caused dosedependant slight increase in viability of black Aspergilli (Fig. 1).
Methods. The Escherichia coli strain BL21(DE3) star transformed with plasmid pET-3c containing Gal-3 coding sequence and ampicillin resistance, was a kind gift from $\mathrm{Dr}$ Hakon Leffler. Expression of Gal-3 in these bacteria was induced by incubation ( 3 hours) with 0.5 mM IPTG. rh-Gal-3 was isolated from the lysate of induced bacteria on lactosyl-Sepharose column. Lactose was removed from rh-Gal-3 fractions by dialysis and SDS-PAGE and Western-blot analysis was used to confirm successful production and purification of rh-Gal-3.

A modified broth dilution method for susceptibility testing against Aspergillus (EUCAST-AST-ASPERGILLUS) was employed in this study [4]. Dilutions of AMB $(0.015-16 \mu \mathrm{g} / \mathrm{mL})$ and Gal-3 (8$520 \mu \mathrm{g} / \mathrm{mL}$ ) in RPMI 1640 with $2 \%$ glucose inoculated with conidial suspension of black Aspergilli $\left(1-2.5 \times 10^{5} \mathrm{CFU} / \mathrm{mL}\right)$ were incubated for $48 \mathrm{~h}$ at $35^{\circ} \mathrm{C}$. Upon incubation MTS reagent was added and plates were incubated for $3 \mathrm{~h}$ at at $35^{\circ} \mathrm{C}$. The absorbance was measured using a microplate reader (Labsystem iEMS, type 1404) at a wavelength of $492 \mathrm{~nm}$. All tests were performed in triplicate and viability of Aspergilli was expressed as percentage of control (untreated Aspergilli).

Table 1. The MIC values of amphotericin $B$ and galectin-3 after the treatment of black Aspergilli

\begin{tabular}{r|r|}
\hline $\begin{array}{r}\text { Aspergillus (Nigri) } \\
\text { A. brasiliensis ATCC } 16404\end{array}$ & $\begin{array}{r}\text { MIC AMB } \\
(\mu \mathrm{g} / \mathrm{mL})\end{array}$ \\
\hline A. piperis & 0.5 \\
\hline A. tubingensis & 0.25 \\
\hline A. welwitchiae & 0.25 \\
\hline A. niger & 0.25 \\
\hline A. luchuensis & 0.25 \\
\hline
\end{tabular}

Conclusion. Our preliminary results shows that Gal-3 may have antifungal activity against black Aspergilli that is species related and does not involve binding to ergosterol

\section{References}

[1] Varga et al., 2011, Stud Mycol 69(1) :1-17.

[2] Almeida et al, 2017. Nat. Commun 8(1), 1968.

[3] Sivashanmugam et al., 2009, Protein Sci. 18(5): 936-948.

[4] Arendrup et al., EUCAST E.DEF 9.3.1 2017, www.EUCAST.org 